\title{
Serum Concentrations of BNP and ANP in Patients with Thyrotoxicosis
}

\author{
KEIKO KATO, HITOMI MURAKAMI, OSAMU ISOZAKI, TOSHIO TSUSHIMA AND KAZUE TAKANO \\ Department of Endocrinology, Clinical Institute of Endocrinology, Tokyo Women's Medical University
}

\begin{abstract}
Serum BNP (brain naturiuretic peptide) and ANP (atrial natriuretic peptide) levels are reportedly elevated in patients with thyrotoxicosis. The increases may not be due to thyrotoxicosis itself but to secondary cardiovascular changes such as chronic heart failure (HF) or atrial fibrillation (AF) which frequently accompany thyrotoxicosis. We measured serum ANP and BNP levels in 130 patients with thyrotoxicosis and correlated them with HF severity and thyroid function. Thirty-seven normal subjects served as controls. Serum BNP levels in thyrotoxic patients were significantly higher than those in control subjects and significantly correlated with serum free T4, free T3 and ANP levels. In untreated Graves' disease serum BNP level was significantly elevated in patients with HF or AF. Multiple regression analysis revealed that $\mathrm{HF}$, free T4, female gender and AF are independent contributing factors to the elevated BNP level, and that these four factors contributed about $40 \%$. On the other hand, HF and AF were contributing variables for ANP level but the overall contribution of these factors was only $10 \%$. After normalization of thyroid function, serum BNP levels were normalized in 70.5\% of Graves' patients. BNP level in euthyroid state was dependent on the presence of HF and the BNP value before therapy, but not on thyroid hormone levels or AF. These data suggest that the cardiovascular condition is the major factor responsible for the elevated serum BNP and ANP levels in thyrotoxic patients, while thyrotoxicosis itself is an independent but minor contributing factor. Thus, the determination of serum BNP levels in thyrotoxic patients is useful for monitoring cardiovascular conditions of HF.
\end{abstract}

Key words: Thyrotoxicosis, Graves' disease, Brain naturiuretic peptide (BNP), Atrial natriuretic peptide (ANP)

(Endocrine Journal 56: 17-27, 2009)

HUMAN cardiomyocytes produce and secrete a family of related peptide hormones such as ANP (atrial natriuretic peptide) and BNP (brain natriuretic peptide or B-type natriuretic hormone) which have potent diuretic, natriuretic and vascular relaxing effects [1-3]. They also have several physiological actions, the most important being: a) to decrease blood pressure; b) to increase natriuresis and diuresis; c) to inhibit the release or action of several hormones including those of the renin-angiotensin-aldosterone system, endothelin and vasopressin. The production and secretion of both ANP and BNP are regulated by a number of factors. Importantly, serum concentrations of both peptides in-

Received: May 15, 2008

Accepted: August 25, 2008

Correspondence to: Keiko KATO, Department of Medicine, Institute of Clinical Endocrinology, Tokyo Women's Medical University, 8-1 Kawada-cho, Shinjuku-ku, Tokyo 162-8666, Japan crease in patients with cardiac failure. ANP is released into circulation in response to increased atrial distension or stretching $[4,5]$. Furthermore, it has been shown that the production of ANP is increased by hormonal factors including thyroid hormone. Actually, hyper- or hypothyroidism is associated with altered serum ANP levels [6-11].

Another cardiac natriuretic peptide, BNP, is produced mainly from the ventricle in response to volume expansion, pressure overload, and elevated endodiastolic pressure $[12,13]$. Serum concentrations of BNP are elevated in patients with chronic heart failure in association with the degree of severity [14], and serum BNP level is a useful marker of cardiac function $[14,15]$. Furthermore, BNP production, is modified by many factors including angiotensin II, endothelin I, [16], hypoxia [17] and cytokines [18]. In addition, thyroid hormone stimulates both the synthesis and release of BNP [19-22]. Thus, serum BNP levels are 
Table 1. Clinical characteristics of patients and control subjects

\begin{tabular}{|c|c|c|c|c|c|c|c|}
\hline & $\mathrm{M} / \mathrm{F}^{*}$ & $\begin{array}{l}\text { Age } \\
\text { (yrs) }\end{array}$ & Pulse/min & $\begin{array}{c}\text { Systolic BP } \\
(\mathrm{mmHg})\end{array}$ & $\begin{array}{l}\text { Diastolic BP } \\
(\mathrm{mmHg})\end{array}$ & $\begin{array}{c}\text { Free T4 } \\
(\mathrm{ng} / \mathrm{dl})\end{array}$ & $\begin{array}{l}\text { Free T3 } \\
(\mathrm{pg} / \mathrm{ml})\end{array}$ \\
\hline Control Subjects & $13 / 24$ & $43.0 \pm 14.6$ & $75 \pm 9$ & $118 \pm 14$ & $71 \pm 10.0$ & $\begin{array}{c}1.20(0.90-1.40) \\
(\mathrm{N}=37)\end{array}$ & $\begin{array}{c}3.00(2.80-3.30) \\
(\mathrm{N}=36)\end{array}$ \\
\hline Untreated Graves' & $25 / 92$ & $45.7 \pm 12.7$ & $92.8 \pm 17.6^{* *}$ & $129 \pm 18$ & $74 \pm 13$ & $\begin{array}{c}4.10(2.60-6.00)^{\$} \\
(\mathrm{~N}=115)\end{array}$ & $\begin{array}{c}11.30(6.65-17.5)^{\$} \\
(\mathrm{~N}=117)\end{array}$ \\
\hline Painless thyroiditis & $3 / 4$ & $43.1 \pm 7.4$ & $90.0 \pm 15.9 * *$ & $139 \pm 24$ & $73 \pm 29$ & $\begin{array}{c}4.40(3.50-4.70)^{\mathrm{S}} \\
(\mathrm{N}=7)\end{array}$ & $\begin{array}{c}9.50(9.30-11.36)^{\$} \\
(\mathrm{~N}=7)\end{array}$ \\
\hline Subacute thyroiditis & $0 / 6$ & $44.7 \pm 10.1$ & $85.3 \pm 22.3$ & $122 \pm 20$ & $70 \pm 12$ & $\begin{array}{c}3.00(1.85-5.05)^{\mathrm{S}} \\
(\mathrm{N}=6)\end{array}$ & $\begin{array}{c}8.40(5.30-11.15)^{\$} \\
(\mathrm{~N}=6)\end{array}$ \\
\hline
\end{tabular}

\# Gender ratio was expressed as number of male and female (M/F) and age in year, pulse rate and blood pressure (BP) were expressed as mean \pm SD.

* Male to female ratio of the patients with untreated Graves' disease was not statistically different from that of control patients ( $\mathrm{P}=0.1244$, Fisher's exact test $)$.

** Significantly higher than control subjects $(\mathrm{P}<0.05$, Dunnett's test).

\# Serum free T4 and free T3 are shown as median (lower and upper intraquartile). The numbers of determinations are shown as N.

\$Free T4 and FT3 levels after Box-Cox transformation in untreated patients with Graves' disease, painless thyroiditis and subacute thyroiditis were significant higher than those of control patients by Dunnett's multiple comparison test $(\mathrm{P}<0.05)$.

elevated in hyperthyroid patients [22], and the circulating levels are positively correlated with serum T4 levels in rats treated with T4 [20]. Furthermore, there was a positive correlation between serum levels of $\mathrm{N}$-terminal-pro-B-type natriuretic peptide (N-terminal 76 amino acids fragment of pro-BNP) levels and serum free T4 estimates in patients including both hypoand hyperthyroidism [21]. However, the hemodynamic changes such as heart failure in thyrotoxicosis may also affect circulating BNP levels. Therefore, we measured serum BNP and ANP levels in a large number of patients with thyrotoxicosis, and correlated them with serum thyroid hormone levels, the renin-aldosterone axis, and with the degree of severity of heart failure.

\section{Subjects and Methods}

\section{Study Subjects}

One hundred thirty patients with untreated thyrotoxicosis seen at Tokyo Womens' Medical University Hospital and at the affiliated hospitals were studied. The patients include 117 Graves' disease (female 92 females, and 25 males), 7 painless thyroiditis (4 females and 3 males), and 6 subacute thyroiditis (6 females). Patients with painless thyroiditis and those with subacute thyroiditis were examined in the thyrotoxic phase. None of these patients had renal failure and other metabolic or the other endocrine disorders.
Gender, age, blood pressure and pulse rate of the patients are shown in Table 1. Heart failure severity was clinically evaluated according to the New York Heart Association (NYHA) classification. Thirty-seven age-matched normal subjects served for controls. They were arbitrarily assigned as NYHA class 0 for statistical analysis.

\section{Hormone determinations}

Circulating BNP and ANP levels were determined with two-site immunoradiometric assay (IRMA) kits (Shionogi, Osaka). Serum levels of thyroid hormone levels (free T3, and free T4), TSH, and aldosterone, were measured by RIA. TSH-receptor antibody (TRAb) was measured using a commercial TRAB kit (Yamasashoyu Co. Ltd., Chiba).

\section{Statistical analysis}

Clinical characteristics such as age, pulse rate and blood pressure are expressed as means \pm SD. Serum thyroid hormones, BNP, ANP, plasma rennin activity (PRA) and aldosterone levels are expressed as median and intraquartile range (IQR). They were subjected to Cox-Box transformation in order to improve the fit for normal distribution before statistical analyses. Difference of gender ratio between groups was assessed by Fisher's exact test. Comparisons of hormone levels to control subjects were conducted by Dunnett's multiple 


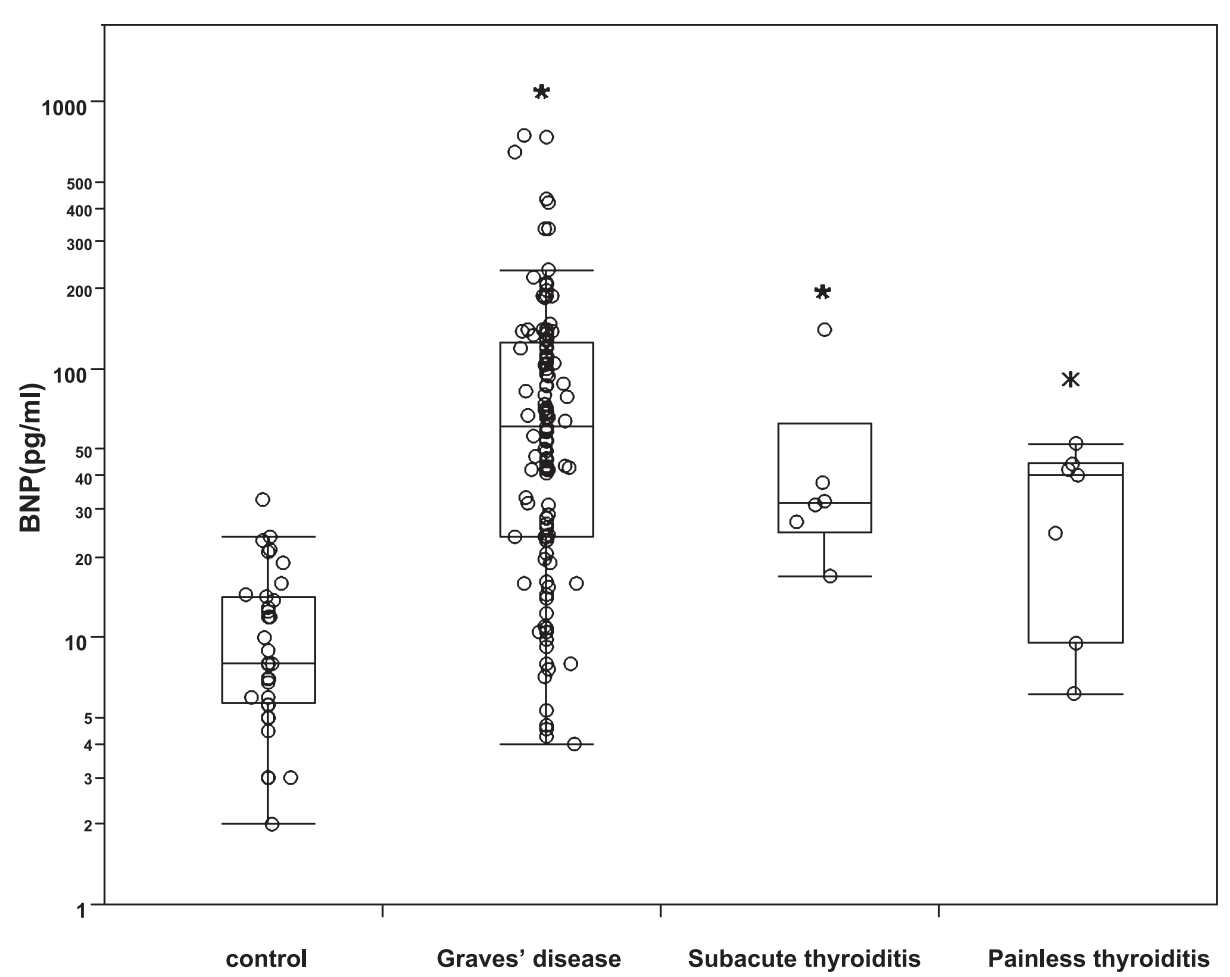

Fig. 1. Serum BNP levels in patients with untreated Graves' disease, subacute thyroiditis and painless thyroiditis. The box plots represent the median and IQR ( $25^{\text {th }}$ to $75^{\text {th }}$ percentile) and the whiskers represent the $10^{\text {th }}$ and $90^{\text {th }}$ percentile, respectively.

* Serum BNP levels after Box-Cox transformation in untreated Graves' disease, painless thyroiditis and subacute thyroiditis were significant higher than those of control patients by Dunnett's multiple comparison test $(\mathrm{P}<0.05)$.

comparison test. Differences between the two groups were carried out by Student's unpaired $t$ test or ANOVA with post hoc analysis. The factors independently associated with serum BNP were assessed by multiple regression analysis with stepwise methods. All analyses were performed using a computer program (JMP version 5.01, SAS Institute, Tokyo, Japan). P value less than 0.05 was considered to be significant.

\section{Results}

\section{Clinical characteristics of the subjects}

As shown in Table 1 the male to female ratio of untreated patients with Graves' disease was not different from that of control subjects. Pulse rate in patients with untreated Graves' disease and painless thyroiditis were significantly higher than that in control subjects. As shown in the Table, serum free T4 and free T3 levels in thyrotoxic patients were significantly $(\mathrm{P}<0.05)$ higher than those of control subjects. TRAb was posi- tive in all of the patients with Graves' disease.

\section{Serum BNP, ANP, PRA and PAC in thyrotoxic patients}

As shown in Fig. 1, BNP levels in patients with untreated Graves' disease, painless thyroiditis and subacute thyroiditis were significantly higher compared with those in control subjects $(\mathrm{P}<0.05)$. The ANP level in untreated patients with Graves' disease was also slightly but significantly elevated compared to that in control patients (Table 2). Although not shown in the table, serum ANP level in patients with painless thyroiditis $(\mathrm{N}=6)$ was $9.6(5.0-35.0)$ was not different from that in control. The ANP levels in patients with subacute thyroiditis were not determined. Plasma aldosterone concentration (PAC) in untreated Graves' disease was significantly higher than that in controls, but there was no difference in plasma renin activity. PRA and PAC in subacute thyroiditis and painless thyroiditis were not determined. 
Table 2. Serum ANP, plasma renin activity (PRA) and plasma aldosterone concentration (PAC) in Graves' patients and control subjects

\begin{tabular}{lccc}
\hline & ANP & PRA & PAC \\
\hline Control & $13.2(8.40-19.0)$ & $0.90(0.40-1.825)$ & $6.65(4.875-8.35)$ \\
& $(\mathrm{N}=37)$ & $(\mathrm{N}=30)$ & $(\mathrm{N}=26)$ \\
Untreated Graves' & $15.80(11.7-25.73)^{*}$ & $1.50(0.50-4.275)$ & $9.05(6.95-12.0)^{*}$ \\
& $(\mathrm{~N}=84)$ & $(\mathrm{N}=88)$ & $(\mathrm{N}=82)$ \\
\hline
\end{tabular}

Serum ANP, plasma renin activity and plasma aldosterone concentration (PAC) are shown as median (lower and upper intraquartile). Number of determinations is shown as $\mathrm{N}$.

* Values after Box-Cox transformation were significantly higher than in control subjects $(\mathrm{P}<0.05$, Student's t test).

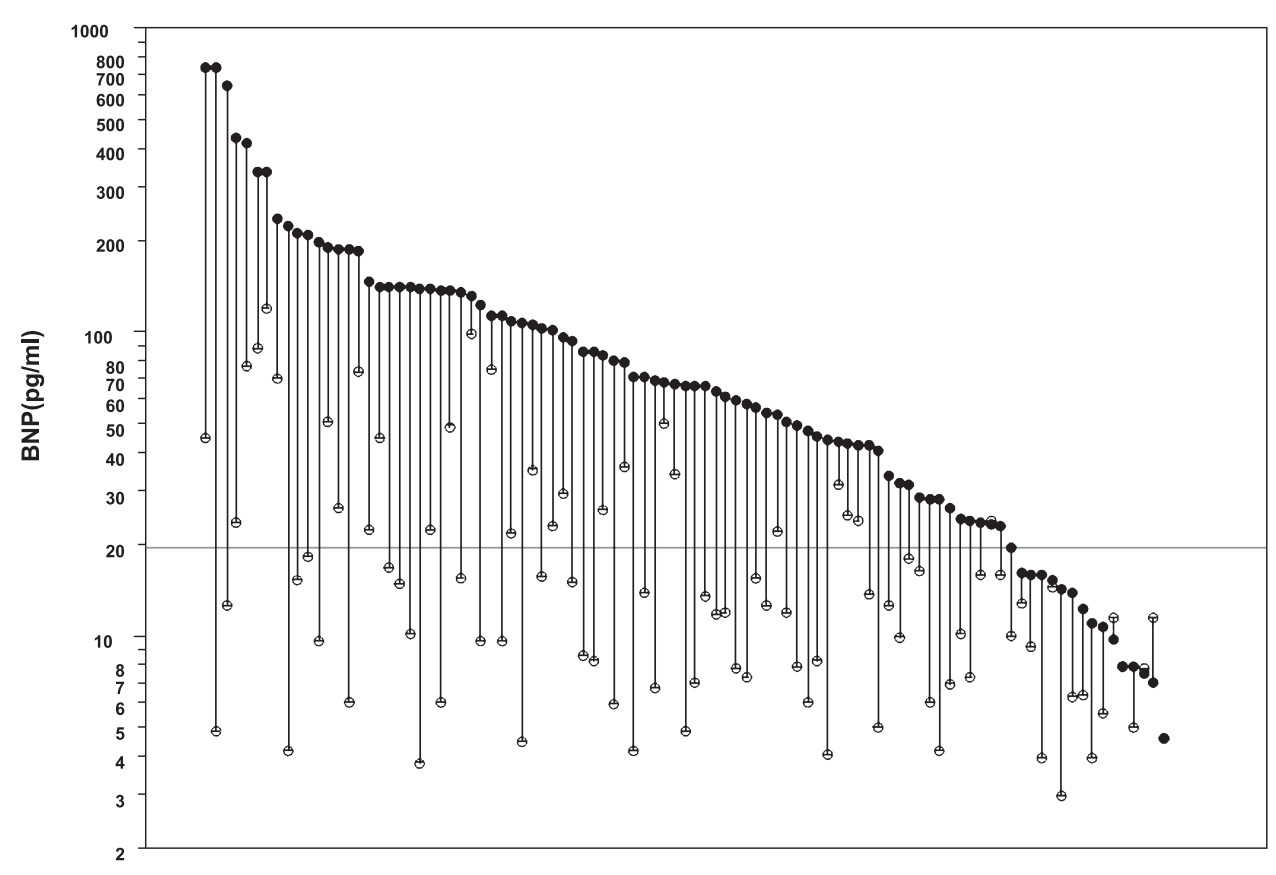

Fig. 2. Serum BNP levels before $(\bigcirc)$ and after $(\bigcirc)$ therapy in patients with Graves' disease.

Serum BNP levels decreased significantly in euthyroid patient after initiation of antithyroid therapy $(\mathrm{P}=0.0001)$. The BNP levels decreased to normal range (lower than $20 \mathrm{pg} / \mathrm{ml}$ ) in 67 out of 95 patients.

\section{Effects of thyrotoxicosis on serum BNP levels}

We next compared serum BNP levels in thyrotoxic state to those in euthyroid state after antithyroid therapy in patients with Graves' disease. Serum samples were obtained before and after $5.7 \pm 2.3$ (mean $\pm \mathrm{SD}$ ) months after the initiation of therapy with methimazole or propylthiouracil. Out of 117,95 patients had become euthyroid judged by normal fT3, free fT4 and TSH levels (TSH $>0.3 \mathrm{mU} / \mathrm{ml})$. As shown in Fig. 2, serum BNP concentration decreased significantly after therapy and in $70.5 \%$ (67 out of 95) patients the levels were within normal range (less than $20 \mathrm{pg} / \mathrm{ml}$ ).
Association of BNP and ANP levels with thyroid hormone levels, plasma renin activity (PRA) and plasma aldosterone concentration (PAC) is shown in Table 3. Serum BNP levels correlated significantly with serum free T4, free T3 and ANP, but not with PRA and PAC in all subjects. As judged by adjusted R square, free $\mathrm{T} 4$ and free $\mathrm{T} 3$ may contribute serum BNP levels up to more than $30 \%$ in all subjects. Serum ANP correlated with free T3 and serum BNP levels significantly. However, the correlations of ANP with these variables were very weak and the contribution of these factors to ANP levels was about $2 \%$ as judged by the adjusted $\mathrm{R}$ square shown in Table 3 panel $\mathrm{A}$. 
Table 3. Associations of BNP and ANP with serum hormone levels

A. All subjects

\begin{tabular}{lcccc}
\hline \multirow{2}{*}{ Variables } & \multicolumn{3}{c}{ BNP } & \multicolumn{2}{c}{ ANP } \\
\cline { 2 - 5 } & Adjusted R ${ }^{2}(\mathrm{~N})$ & $\mathrm{P}$ & \multicolumn{1}{c}{ Adjusted R $^{2}(\mathrm{~N})$} & $\mathrm{P}$ \\
\hline Free T4 & $0.3613(163)$ & $<0.0001$ & $0.0204(128)$ & 0.0579 \\
Free T3 & $0.3596(165)$ & $<0.0001$ & $0.0239(129)$ & 0.0441 \\
PRA & $0.0087(117)$ & 0.1748 & $0.0037(99)$ & 0.2465 \\
PAC & $0.0143(107)$ & 0.8798 & $0.0096(89)$ & 0.7079 \\
ANP & $0.0736(129)$ & 0.0011 & - & - \\
BNP & - & - & $0.0736(129)$ & 0.0011 \\
\hline
\end{tabular}

B. Patients with untreated Graves' disease

\begin{tabular}{lcccc}
\hline \multirow{2}{*}{ Variables } & \multicolumn{2}{c}{ BNP } & \multicolumn{2}{c}{ ANP } \\
\cline { 2 - 5 } & Adjusted R $(\mathrm{N})$ & $\mathrm{P}$ & $\operatorname{Adjusted~R}^{2}(\mathrm{~N})$ & $\mathrm{P}$ \\
\hline Free T4 & $0.1655(115)$ & $<0.0001$ & $0.0119(83)$ & 0.8552 \\
Free T3 & $0.1306(117)$ & $<0.0001$ & $0.0011(84)$ & 0.7559 \\
PRA & $0.0092(88)$ & 0.1748 & $0.0208(69)$ & 0.1226 \\
PAC & $0.0122(82)$ & 0.8798 & $0.0087(63)$ & 0.4968 \\
ANP & $0.1205(84)$ & 0.0007 & - & - \\
BNP & - & - & $0.1205(84)$ & 0.0007 \\
\hline
\end{tabular}

All data were subjected to Cox-Box transformation in order to fit for normal distribution as described in Materials and Methods. Linea regressions of BNP and ANP with the biological variables were calculated for all subjects (A) and for patients with Graves' disease (B). Adjusted $\mathrm{R}^{2}$ and the number of observations (N) are shown in first column. $\mathrm{P}$ values for linear regressions are also shown in the next column. BNP levels in all subjects significantly correlated with serum free T4, free T3 and ANP levels, while ANP showed weak correlations with serum free T3 levels. BNP levels in patients with untreated Graves' disease correlated with serum free T4, free T3 and ANP levels but ANP had no significant correlation with free $\mathrm{T} 4$ and free $\mathrm{T} 3$.

As shown in panel B of Table 3, analyses of BNP and ANP levels in patients with untreated Graves' showed a weaker correlation to thyroid hormone levels. The contribution of free T4 to serum BNP levels was $17 \%$ as judged by $\mathrm{R}$ square. In these patients, ANP levels correlated with BNP but not thyroid hormone levels. These data suggested that factors other than serum thyroid hormones may contribute to BNP and ANP levels in untreated patients with Graves' disease.

\section{Effects of heart failure on serum BNP and ANP levels}

It is well established that circulating BNP and ANP levels positively correlated with the severity of heart failure. The majority of untreated Graves' patients were judged as class I or II of functional state (NYHA) and only 7 patients were classified as class III. There was no patient with class IV. As shown in Fig. 3, BNP concentrations were significantly increased in patients classified as NYHA class III $(\mathrm{P}<0.05)$, which is similar to the results reported for the patients with cardiovascular diseases [14]. In contrast to BNP, there was no significant difference from controls in ANP concentrations in patients classified as NYHA Class III (data not shown).

\section{Effects of atrial fibrillation on serum BNP and ANP levels}

We then studied the effect of atrial fibrillation (AF) on BNP and ANP levels. As shown in Table 4, serum BNP and ANP levels were significantly higher in untreated Graves' patients with atrial fibrillation compared with patients without fibrillation, although both serum free T4 and free T3 levels were comparable. These results suggest that atrial fibrillation may be one of the independent factors responsible for the increased serum BNP and ANP levels in thyrotoxic patients.

\section{Effects of female gender on serum BNP and ANP levels}

As shown in Table 5, serum BNP levels were significantly higher in female patients. However, serum ANP, free T4 and free T3 levels showed no significant difference between the two genders. The results suggest that gender is also a contributing factor for the increased serum BNP level.

\section{Multiple regression analyses of serum $B N P$ and $A N P$ levels in Graves' disease}

The above data suggested that thyroid hormones, heart failure, atrial fibrillation and female gender contribute to serum BNP and ANP levels. In order to determine the potency of these factors in determining BNP levels, we analyzed these data using multiple regression analysis.

As shown in Table 6, congestive heart failure (NYHA III) is the most potent contributing factor as judged by stepwise analysis. Serum FT4 levels also contributes to serum BNP levels in an independent manner. Female gender and atrial fibrillation also contributed significantly to serum BNP levels. As can 


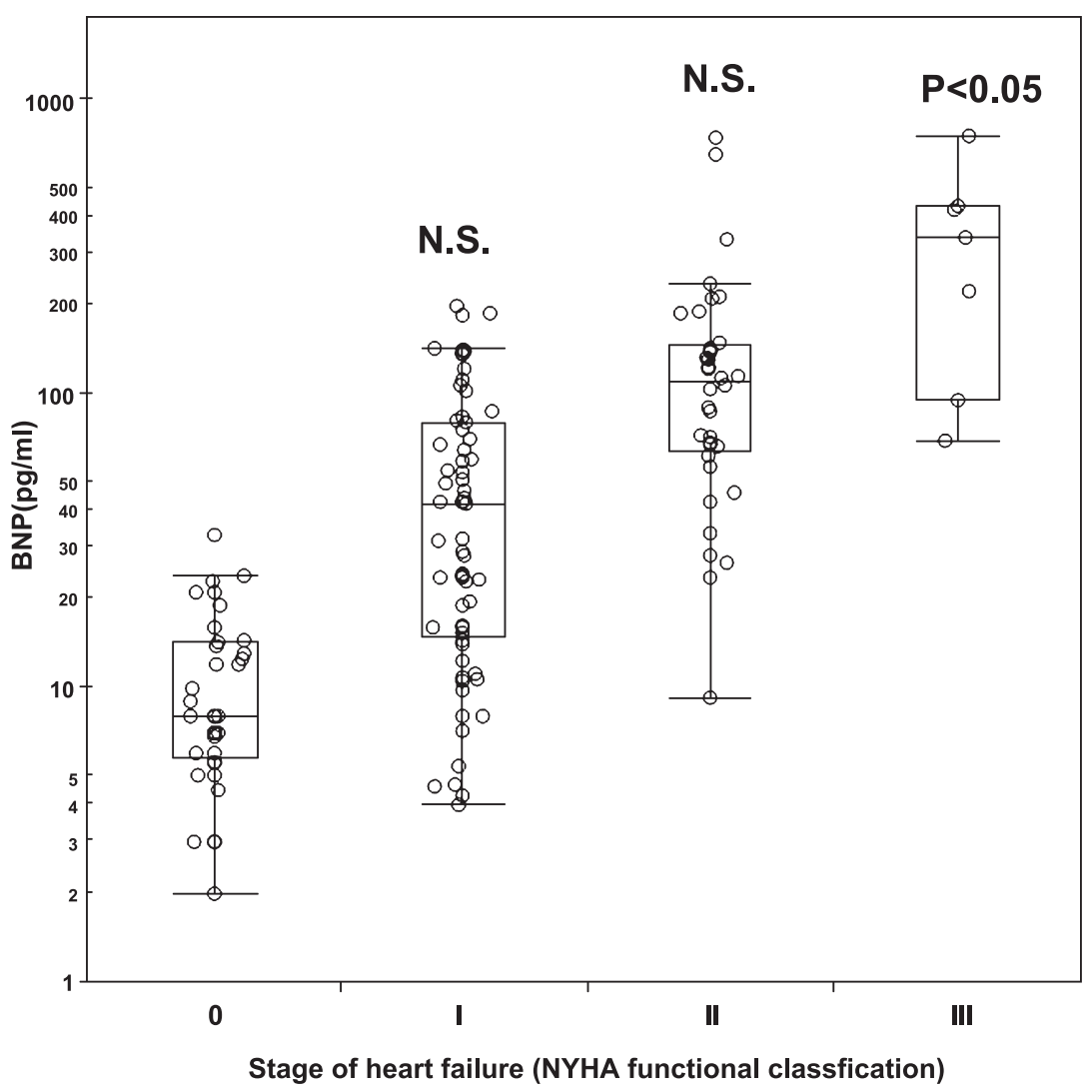

Fig. 3. Serum BNP levels in patient with Graves' disease in relation to heart failure.

Serum levels of BNP in 117 untreated Graves disease patients, divided according to NYHA class (Class I N $=67, \mathrm{II} N=43$, and III $\mathrm{N}=7$ ) and class 0 in 37 control subjects (Class $0 \mathrm{~N}=37)$. The box plots represent the median and IQR $\left(25^{\text {th }}\right.$ to $75^{\text {th }}$ percentile) and the whiskers represent the $10^{\text {th }}$ and $90^{\text {th }}$ percentile, respectively.

* Serum BNP levels in patients classified as III were significantly higher than those in Class I patients $(\mathrm{P}<0.05$, Dunnett's multiple comparison test)

Table 4. Effects of atrial fibrillation (AF) on serum BNP and ANP levels in untreated patients with Graves' disease

\begin{tabular}{lccc}
\hline & atrial fibrillation $(+)$ & atrial fibrillation $(-)$ & $\mathrm{P}^{*}$ \\
\hline BNP $(\mathrm{pg} / \mathrm{ml})$ & $171.00(92.72-424.75)$ & $54.70(23.30-113.00)$ & $\mathrm{P}<0.05$ \\
& $(\mathrm{~N}=10)$ & $(\mathrm{N}=107)$ & \\
ANP $(\mathrm{pg} / \mathrm{ml})$ & $31.50(16.75-91.08)$ & $14.90(11.38-22.25)$ & $\mathrm{P}<0.05$ \\
& $(\mathrm{~N}=10)$ & $(\mathrm{N}=74)$ & \\
Free T4 $(\mathrm{ng} / \mathrm{dl})$ & $4.350(3.245-6.100)$ & $4.100(2.600-6.100)$ & N.S.** \\
& $(\mathrm{N}=10)$ & $(\mathrm{N}=105)$ & \\
Free T3 $(\mathrm{pg} / \mathrm{ml})$ & $12.00(8.575-16.300)$ & $11.300(6.600-17.800)$ & N.S.** \\
& $(\mathrm{N}=10)$ & $(\mathrm{N}=107)$ & \\
\hline
\end{tabular}

Serum BNP, ANP, free T4 and free T3 levels were compared between untreated Graves' patients with and without atrial fibrillation. The values are median (lower and upper intraquartile). Numbers of observations are also shown as $\mathrm{N}$. * Statistical analyses were conducted by Student's $t$ test after Box-Cox transformation. N.S. means not significant. 
Table 5. Effect of female gender on serum BNP, ANP, free thyroxine (T4) and free triiodothyronine (T3)

\begin{tabular}{lccc}
\hline & Male & Female & P* \\
\hline BNP $(\mathrm{pg} / \mathrm{ml})$ & $41.00(17.25-76.35)$ & $68.9(24.57-135.0)$ & $\mathrm{P}<0.05$ \\
& $(\mathrm{~N}=25)$ & $(\mathrm{N}=92)$ & \\
ANP $(\mathrm{pg} / \mathrm{ml})$ & $17.2(11.30-29.20)$ & $15.6(11.80-24.45)$ & N.S.** \\
& $(\mathrm{N}=19)$ & $(\mathrm{N}=65)$ & \\
Free T4 $(\mathrm{ng} / \mathrm{dl})$ & $4.20(2.35-5.50)$ & $4.100(2.600-6.700)$ & N.S.** \\
& $(\mathrm{N}=25)$ & $(\mathrm{N}=90)$ & \\
Free T3 $(\mathrm{pg} / \mathrm{ml})$ & $11.00(6.700-15.850)$ & $11.35(6.625-17.725)$ & N.S.** \\
& $(\mathrm{N}=25)$ & $(\mathrm{N}=92)$ & \\
\hline
\end{tabular}

Serum BNP, ANP, free T4 and free T3 levels were compared between male and female patients with untreated Graves' disease. The values are median (lower and upper intraquartile). Numbers of observations are also shown as N. *Statistical analyses were conducted by Student's $t$ test after BoxCox transformation. N.S. means not significant.

be seen in adjusted $\mathrm{R}$ square (coefficient of determination), overall contribution of these four factors was estimated as $42 \%$.

We also analyzed the contributing factors for serum ANP in untreated Graves' patients. The results are shown in Table 6 panel B. Atrial fibrillation and grade II or III heart failure contributed ANP levels but their contributions was only about $10 \%$ in sum.

The same regression analysis was also employed for serum BNP levels in euthyroid Graves' patients because serum BNP levels were still above normal range in some patients. Table 7 shows that serum BNP levels before therapy is the most potent contributing factor. Heart failure (NYHA III) was the second contributing factor, and gender also contributed to BNP level after therapy. However, neither FT4 levels nor presence of atrial fibrillation before therapy contributed to BNP levels after therapy. Thus, cardiovascular conditions before anti-thyroid drug therapy may have some influence on serum BNP levels in a part of Graves' patients.

\section{Discussion}

It is well established that thyroid hormone has a profound effect on cardiovascular hemodynamics. Thyrotoxicosis is associated with decreases in systemic vascular resistance, increases in heart rate, left ventricular ejection, cardiac contractility and circulating blood volume. High plasma renin activity and low or normal aldosterone levels have been reported [9,
23], which was not confirmed, however, in the present study.

Heart failure occurs mostly in elderly or in patients having underlying heart disease or atrial fibrillation. However, heart failure can develop in some patients with no known heart disease and in the absence of atrial fibrillation. Confirming the earlier reports, the present study showed significant higher serum ANP levels in untreated Graves' disease. Especially, the values in Graves' patients with atrial fibrillation were significantly higher than those in patients without atrial fibrillation, which is similar to the report by Czekalski et al. [10]. They suggested that the ANP level in thyrotoxic patients is likely to be affected more by circulatory dynamics, such as auricular fibrillation than by thyroid hormone levels. Supporting the report, the present study also demonstrated that serum ANP levels in untreated Graves' disease had no significant correlation with serum thyroid hormone levels, and multiple regression analyses demonstrated the contributions of the presence of atrial fibrillation and heart failure (NYHA II and III). Thus, the direct effect of thyroid hormone on serum ANP level may be minor, if any.

There are only a few reports for BNP levels in patients with thyrotoxicosis [26-28]. In patients with hyperthyroidism the circulating BNP levels increased, and the values were positively correlated with serum thyroxine levels [20]. Schultz et al. have recently reported higher concentrations of N-terminal pro BNP in patients with hyperthyroidism than in those with hypothyroidism [21]. They also showed a positive associa- 
Table 6. Stepwise regression analysis with BNP and ANP levels as the dependent variable in untreated patients with Graves' disease

\section{A. Stepwise regression analysis for serum BNP levels}

Adaptation of parameters by Stepwise method

\begin{tabular}{|c|c|c|c|}
\hline & Parameter & Significance Probability & $\mathrm{R}^{2}$ \\
\hline $1 \mathrm{st}$ & NYHA $\{$ II-III $\}$ & 0 & 0.2729 \\
\hline $2 \mathrm{nd}$ & Free T4 (transformed) & 0 & 0.417 \\
\hline $3 \mathrm{rd}$ & Gender $\{\mathrm{M}-\mathrm{F}\}$ & 0.0968 & 0.4315 \\
\hline 4 th & AF $\{$ without-with $\}$ & 0.118 & 0.4442 \\
\hline \multicolumn{4}{|c|}{ Estimates for the overall formula for serum BNP levels } \\
\hline variables & Estimate & F value & $P$ value \\
\hline Free T4 (transformed) & 9.17952 & 25.851 & 0.001 \\
\hline NYHA $\{0 \& I-I I \& I I I\}$ & -33.5774 & 14.353 & 0.001 \\
\hline Gender $\{\mathrm{M}-\mathrm{F}\}$ & -10.108 & 3.441 & 0.0663 \\
\hline NYHA $\{$ II-III $\}$ & -19.942 & 2.961 & 0.0881 \\
\hline AF $\{$ without-with $\}$ & -14.666 & 2.483 & 0.118 \\
\hline Free T3 (transformed) & 0 & 0.833 & 0.3496 \\
\hline NYHA $\{0-\mathrm{I}\}$ & 0 & 0.009 & 0.9228 \\
\hline intercept & 47.10866 & 0 & 1 \\
\hline
\end{tabular}

In stepwise regression, independent variables as shown above were tested. The combination as shown in the table was selected by forward and backward method. The strongest correlation was obtained by the program and the $\mathrm{F}$ values were more than 2 .

The multiple regression formula for transformed BNP is as follows.

$182.417-19.942 \times$ NYHA(II: $1, \quad$ III: -1$)-33.5774 \times$ NYHA $\quad(0 \& \mathrm{I}: \quad 1, \quad$ II\&III: -1$)+9.142 \times$ FT4 (transformed) $-10.108 \times($ Male: 1 , Female: -1$)-14.666$ atrial fibrillation (without: 1 , with: -1 )

The coefficient of determination (R2) was 0.442 and the adjusted R2 was 0.4187 . Therefore serum BNP levels were determined about $42 \%$ by these variables in the model.

B. Stepwise regression analysis for serum ANP levels in untreated patients with Graves' disease

Adaptation of parameters by Stepwise method

\begin{tabular}{|c|c|c|c|}
\hline & Parameter & Significance Probability & $\mathrm{R}^{2}$ \\
\hline $1 \mathrm{st}$ & AF \{without-with $\}$ & 0.0039 & 0.0982 \\
\hline $2 n d$ & NYHA $\{0 \& \mathrm{I}-\mathrm{II} \& \mathrm{III}\}$ & 0.0864 & 0.131 \\
\hline \multicolumn{4}{|c|}{ Estimates for the linea formula for serum ANP levels } \\
\hline variable & Estimate & F value & $P$ value \\
\hline AF \{without-with\} & -4.1588 & 4.64 & 0.0342 \\
\hline NYHA $\{0 \& \mathrm{I}-\mathrm{II} \& \mathrm{III}\}$ & -2.21904 & 3.015 & 0.0864 \\
\hline NYHA $\{$ II-III $\}$ & 0 & 1.127 & 0.2917 \\
\hline Free T4 (transformed) & 0 & 0.144 & 0.7056 \\
\hline fT3 & 0 & 0.044 & 0.8344 \\
\hline Gender $\{\mathrm{F}-\mathrm{M}\}$ & 0 & 0.008 & 0.931 \\
\hline NYHA $\{0-\mathrm{I}\}$ & 0 & 0.006 & 0.9405 \\
\hline Intercept & 142.0542 & 0 & 1 \\
\hline
\end{tabular}

In stepwise regression, independent variables as shown above were tested. The combination as shown in the table was selected by forward and backward method. The strongest correlation was obtained by the program and the $\mathrm{F}$ values were more than 2 .

The multiple regression formula for transformed ANP is as follows.

$142.0542-4.1588$ atrial fibrillation (without: 1 , with: -1 ) - $2.21904 \times$ NYHA (0\&I: 1 , II\&III: -1 )

The coefficient of determination $\left(\mathrm{R}^{2}\right)$ was 0.1310 and the adjusted $\mathrm{R}^{2}$ was 0.1093 . Therefore presence of heart failure serum BNP levels were determined by these variables to $11 \%$ in the model. 
Table 7. Stepwise regression analysis with BNP levels in euthyroid patients with Graves' disease after therapy

Adaptation of parameters by Stepwise method

\begin{tabular}{|c|c|c|c|}
\hline & Parameter $^{\#}$ & Significance Probability & $\mathrm{R}^{2}$ \\
\hline $1 \mathrm{st}$ & BNP (transformed) & 0 & 0.2729 \\
\hline 2nd & NYHA $\{$ II-III $\}$ & 0.0719 & 0.417 \\
\hline $3 \mathrm{rd}$ & Gender $\{\mathrm{M}-\mathrm{F}\}$ & 0.1518 & 0.4315 \\
\hline \multicolumn{4}{|c|}{ Estimates for the overall formula for serum BNP levels } \\
\hline variables & Estimate & F value & $\mathrm{P}$ value \\
\hline BNP (transformed) ${ }^{\#}$ & 0.068412 & 10.783 & 0.0015 \\
\hline NYHA $\{0 \& I-I I \& I I I\}$ & -3.31721 & 2.549 & 0.0839 \\
\hline NYHA $\{$ II-III $\}$ & -3.36074 & 2.351 & 0.1288 \\
\hline Gender $\{\mathrm{F}-\mathrm{M}\}$ & -1.73982 & 2.089 & 0.1518 \\
\hline Free T4 (transformed) & 0 & 1.026 & 0.3138 \\
\hline AF $\{$ without-with $\}$ & 0 & 0.343 & 0.5595 \\
\hline Free T3 (transformed) & 0 & 0.252 & 0.6173 \\
\hline NYHA $\{0-I\}$ & 0 & 0.105 & 0.7461 \\
\hline Intercept & 47.10866 & 0 & 1 \\
\hline
\end{tabular}

\# The value at pretreatment.

In stepwise regression, independent variables as shown above were tested. The combination as shown in the table was selected by forward and backward method. The strongest correlation was obtained by the program and the F values were more than 2 .

The multiple regression formula for transformed ANP is as follows.

47.10866 - $3.31721 \times$ NYHA (0\&I: 1 , II\&III: -1$)-3.36074 \times$ NYHA (II: 1 , III: -1$)-1.73982 \times($ Female: 1, Male: -1$)$.

The coefficient of determination $\left(\mathrm{R}^{2}\right)$ was 0.2747 and the adjusted $\mathrm{R}^{2}$ was 0.2421 . Therefore serum BNP levels in euthyroid patients after initiation of antithyroid therapy were determined about $27 \%$ by these variables before therapy.

tion between serum fT3 or fT4 level and N-terminal pro BNP levels. The values were not correlated with cardiac output measured by impedance cardiography. However, in another report [22], higher BNP levels in hyperthyroidism were associated with ventricular dysfunction. In our present study using a larger number of patients, we showed a significantly higher than normal BNP levels in patients with untreated Graves' disease, and the values returned to normal range after normalization of thyroid functions in most of the patients. These observations support the notion that the increase in BNP levels in thyrotoxicosis may be due to the direct effect of thyroid hormone on heart, since rat heart responds to thyroid hormone with increased expression of BNP mRNA [19]. Alternatively, production of BNP may be stimulated by hemodynamic changes (HF or AF) induced by thyrotoxicosis. In the present study, we showed by multiple regression analysis that the presence of heart failure (NYHA class III) is the major contributing factor for the elevation of serum
BNP levels, and that thyroid hormone levels (free T4) was the next contributing factor.

There was a slight, but significant increase of serum BNP levels in patients with destructive thyroiditis. This may be due to at least in part to thyrotoxicosis itself because none of them showed any apparent $\mathrm{CH}$ or $\mathrm{AF}$. It is also possible that cytokines produced in destructive thyroiditis affect the production of BNP. Interleukin-6 (IL-6) reportedly stimulates gene expression of BNP and ANP [24].

Of interest, we have demonstrated that female gender is also an independent contributing factor for the elevation of BNP, but we could not demonstrate a gender difference for serum ANP levels. The effect of gender on serum BNP may be accounted for by the effects of estrogen or estrogen-induced substances involved in the production of BNP or degradation of BNP. Further study is required to clarify this point.

In summary, we showed that 1) serum concentration of BNP is elevated in patients with thyrotoxicosis; 2) 
both serum thyroid hormones and cardiovascular dysfunction contribute to the increase of serum BNP levels, but the major contributor is the latter; 3) female gender and atrial fibrillation are also independent contributing factor for the increase of BNP; and 4) increase of circulating ANP levels in hyperthyroidism is largely due to changes in circulatory dynamics.

\section{Acknowledgement}

The present work was supported in part by a grant from the Institute of Growth Science and by a grant from the Ministry of Education and Science.

\section{References}

1. Clerico A, Iervssi G, Mariani G (1999) Clinical relevance of the measurement of cardiac naturiuretic peptide hormones in humans. Horm Metab Res 31: 487-498.

2. Boomsma F, Van den Meiracker AH (2001) Plasma Aand B-type peptides: physiology, methodology, and clinical use. Cardiovasc Res 51: 442-449.

3. Levin ER, Gardner GD, Samson WK (1998) Naturiuretic peptides. New Engl J Med 339: 321-328.

4. Katsube N, Schwarz P, Needleman P (1986) Release of atriopeptin in the rat by vasoconstrictors or water immersion correlates with changes in right atrium pressure. Biochem Biophys Res Commun 134: 178183.

5. Dietz JR (1984) Release of a natriuretic factor from rat heart-lung preparation by atrial distension. Am J Physiol 247: R1093-1096.

6. Tajiri J, Noguchi S, Naomi S, Murakami T, Morita M, Murakami N, Kato R, Umeda T, Sato T (1990) Plasma atrial natriuretic peptide in patients with Graves' disease. Endocrinol Jpn 37: 665-670.

7. Yamaji T, Ishibashi M, Takaku F, Sato F, Kamoi K (1988) Plasma atrial natriuretic peptide in states of altered thyroid function. Endocrinol Jpn 35: 343-348.

8. Suzuki Y, Suzuki H, Ohtake R, Kobori H, Tsuchiya T, Hashigami Y, Shimoda S (1988) Changes in the plasma and urine alpha human atrial natriuretic peptide (alpha hANP) concentration in patients with thyroid disorders. Endocrinol Jpn 35: 907-913.

9. Shigematsu S, Iwasaki $T$, Aizawa $T$, Ishihara $M$, Shinoda T, Yamada T, Sato A, Takemura Y (1998) Plasma atrial natriuretic peptide, plasma renin activity and aldosterone during treatment of hyperthyroidism due to Graves' disease. Horm Metab Res 21: 514-518.

10. Czekalski S, Widecka K, Gozdzik J, Ciechanowski K, Krzyzanowska-Swiniarska B, Gromniak E, Gruszczynska M (1994) Atrial natriuretic peptide and cyclic guanosine monophosphate plasma concentrations in patients with thyrotoxicosis and atrial fibrillation. Effect of short-term methimazole therapy. $J$ Endocrinol Invest 17: 341-346.

11. Koukoulis G, Polymeris A, Tzavara I, Pappas D,
Thalassinos N (2002) Normalization of thyroid hormone levels in patients with either hyper- or hypothyroidism results in a profound change of atrial natriuretic peptide (ANP) levels. Hormones (Athens) 1: 104-112.

12. Baughman K (2002) B-type natriuretic peptide-a window to the heart. New Engl J Med 347: 158-159.

13. Nakagawa O, Ogawa Y, Itoh Y, Suga S, Komatsu Y, Kishimoto I, Nishino K, Yoshimasa T, Nakao K (1995) Rapid transcriptional activation and early mRNA turnover and brain natriuretic peptide in cardiocyte hypertrophy. Evidence for brain natriuretic peptide as an emergency cardiac hormone against ventricular overload. J Clin Invest 96: 1280-1287.

14. Mukoyama M, Nakao K, K Hosoda, S Suga, Y Saito, Y Ogawa, G Shirakami, M Jougasaki, K Obata, H Yasue, et al. (1991) Brain natriuretic peptide as a novel cardiac hormone in humans. Evidence for an exquisite dual natriuretic peptide system, atrial natriuretic peptide and brain natriuretic peptide. J Clin Invest 87: 1402-1412.

15. Remme WJ, Swedberg K (2001) Task Force Report. Guidelines for the diagnosis and treatment of chronic failure. Eur Heart J 22: 1527-1560.

16. Piuhola J, Szokodi I, Ruskoaho H (2007) Endothelin-I and angiotensin II contribute to BNP but not c-fos gene expression to elevated load in isolated mice hearts. Biochem Biophys Acta 1772: 338-344.

17. Weidemann A, Kranke B, Wagner M, Volk T, Willam C, Wiesener MS, Eckart KU, Warnecke C (2008) Hypoxia, via stabilization of hypoxia-inducible factor HIF-alpha is a direct and sufficient stimulus for braintype natriuretic peptide induction. Biochem J 409: 233242.

18. Ma KK, Ogawa T, de Bold AJ (2004) Selective regulation of cardiac brain natriuretic peptide at transcriptional and translational levels by pro-inflammatory cytokines and by conditioned medium derived from mixed lymphocyte reactions via p38 MAP kinase. $J$ Mol Cell Cardio 36: 505-513.

19. Liang F, Webb P, Marimuth A, Zhang S, Gardner DG (2005) Triiodothyronine increases brain natriuretic peptide (BNP) gene transcription and amplifies endothelin dependent BNP gene transcription and hypertro- 
phy in neonatal rat ventricular myocytes. J Biol Chem 278: 15073-15083.

20. Kohno M, Horio T, Yasunari K, Yokokawa K, Ikeda M, Kurihara N, Nishizawa Y, Morii H, Takeda T (1993) Stimulation of brain natriuretic peptide release from the heart by thyroid hormone. Metabolism 42: 1059-1064.

21. Schultz M, Faber J, Kistorp C, Jarløv A, Pedersen F, Wiinberg N, Hildebrandt P (2004) N-terminal-pro-Btype natriuretic peptide (NT-pro-BNP) in different thyroid function states. Clin Endocrinol (Oxf) 60: 54-59.
22. Wei T, Zeng C, Tian Y, Chen Q, Wang L (2005) Btype natriuretic peptide in patients with clinical hyperthyroidism. J Endocrinol Invest 28: 8-11.

23. Asmah BJ, Van Nazaimoon WM, Narazmi K, Tan TT, Khalid Bak (1997) Plasma renin and alsosterone in thyroid diseases. Horm Metab Res 29: 580-583.

24. Tanaka T, Kanda T, Takahashi T, Saegusa S, Moriya J, Kurabayashi M (2004) Interleukin-6-induced reciprocal expression of SERCA and natriuretic peptides mRNA in cultured rat ventricular myocytes. Int Med Res 32: 57-61. 